\title{
Periodic Points of Weaker Meir-Keeler Contractive Mappings on Generalized Quasimetric Spaces
}

\author{
Ing-Jer Lin, ${ }^{1}$ Chi-Ming Chen, ${ }^{2}$ and Erdal Karapınar ${ }^{3,4}$ \\ ${ }^{1}$ Department of Mathematics, National Kaohsiung Normal University, Kaohsiung, Taiwan \\ ${ }^{2}$ Department of Applied Mathematics, National Hsinchu University of Education, Taiwan \\ ${ }^{3}$ Department of Mathematics, Atilim University, Incek, 06836 Ankara, Turkey \\ ${ }^{4}$ Nonlinear Analysis and Applied Mathematics Research Group (NAAM), King Abdulaziz University, Jeddah, Saudi Arabia
}

Correspondence should be addressed to Chi-Ming Chen; ming@mail.nhcue.edu.tw

Received 15 May 2014; Accepted 6 June 2014; Published 3 July 2014

Academic Editor: Jen-Chih Yao

Copyright (C) 2014 Ing-Jer Lin et al. This is an open access article distributed under the Creative Commons Attribution License, which permits unrestricted use, distribution, and reproduction in any medium, provided the original work is properly cited.

By using the weaker Meir-Keeler function $\phi$ and the triangular $\alpha$-admissible mapping $\alpha$, we introduce the notion of $(\alpha-\phi)$-weaker Meir-Keeler contractive mappings and prove a theorem which assures the existence of a periodic point for these mappings on generalized quasimetric spaces.

\section{Introduction and Preliminaries}

Let $X$ be a nonempty set and let $d: X \times X \rightarrow[0, \infty)$. Then $d$ is called a distance function if for every $x, y, z \in X$, satisfies

$$
\begin{aligned}
& \left(d_{1}\right) d(x, x)=0 ; \\
& \left(d_{2}\right) d(x, y)=d(y, x)=0 \Rightarrow x=y ; \\
& \left(d_{3}\right) d(x, y)=d(y, x) ; \\
& \left(d_{4}\right) d(x, z) \leq d(x, y)+d(y, z) .
\end{aligned}
$$

If $d$ satisfies conditions $\left(d_{1}\right)-\left(d_{4}\right)$, then $d$ is called a metric on $X$. If $d$ satisfies conditions $\left(d_{1}\right),\left(d_{2}\right)$, and $\left(d_{4}\right)$, then $d$ is called a quasimetric on $X$. If $d$ satisfies conditions $\left(d_{2}\right)$, $\left(d_{3}\right)$, and $\left(d_{4}\right)$, then $d$ is called a dislocated metric on $X$. If $d$ satisfies conditions $\left(d_{2}\right)$ and $\left(d_{4}\right)$, then $d$ is called a dislocated quasimetric on $X$.

In 2000, Branciari [1] introduced the notion of generalized metric as a natural extension of the concept of a metric, where the triangle inequality condition of a metric had been replaced by a weaker condition, namely, quadrilateral inequality. At the first glance, both metric and generalized metric seem to have almost the same topological properties. Despite the first impression, the generalized metric does possess some fundamental topological feature, such as

$(P 1)$ generalized metric needs not to be continuous;
(P2) a convergent sequence in generalized metric space needs not to be Cauchy;

(P3) generalized metric space needs not to be Haussdorf and hence the uniqueness of limits cannot be guaranteed.

The question whether the analog of existing fixed point results in the literature are still valid in generalized metric space without assuming an extra conditions, such as, continuity of generalized metric function, and/or Hausdorffness of the corresponding space, and so forth. Several authors worked on this interesting questions and this space (e.g., [1-18]).

Definition 1 (see [1]). Let $X$ be a nonempty set and let $d$ : $X \times X \rightarrow[0, \infty)$ be a mapping such that for all $x, y \in X$ and for all distinct points $u, v \in X$, each of them different from $x$ and $y$, one has

(i) $d(x, y)=0$ if and only if $x=y$;

(ii) $d(x, y)=d(y, x)$;

(iii) $d(x, y) \leq d(x, u)+d(u, v)+d(v, y)$ (quadrilateral inequality).

Then $(X, d)$ is called a generalized metric space (or shortly g.m.s). 
We present an example to show that not every generalized metric on a set $X$ is a metric on $X$.

Example 2. Let $X=\{t, 2 t, 3 t, 4 t, 5 t\}$ with $t>0$ as a constant, and we define $d: X \times X \rightarrow[0, \infty)$ by

(1) $d(x, x)=0$, for all $x \in X$;

(2) $d(x, y)=d(y, x)$, for all $x, y \in X$;

(3) $d(t, 2 t)=3 \gamma$;

(4) $d(t, 3 t)=d(2 t, 3 t)=\gamma$;

(5) $d(t, 4 t)=d(2 t, 4 t)=d(3 t, 4 t)=2 \gamma$;

(6) $d(t, 5 t)=d(2 t, 5 t)=d(3 t, 5 t)=d(4 t, 5 t)=(3 / 2) \gamma$,

where $\gamma>0$ is a constant. Then, let $(X, d)$ be a generalized metric space, but it is not a metric space because

$$
d(t, 2 t)=3 \gamma>d(t, 3 t)+d(3 t, 2 t)=2 \gamma
$$

We now introduce the new notion of generalized quasimetric space as follows.

Definition 3. Let $X$ be a nonempty set and let $d: X \times X \rightarrow$ $[0, \infty)$ be a mapping such that for all $x, y \in X$ and for all distinct point $u, v \in X$, each of them different from $x$ and $y$, one has

(i) $d(x, y)=0$ if and only if $x=y$;

(ii) $d(x, y) \leq d(x, u)+d(u, v)+d(v, y)$.

Then $(X, d)$ is called a generalized quasimetric space (or shortly g.q.m.s).

Remark 4. Any generalized metric space is a generalized quasimetric space, but the converse is not true in general.

We present an example to show that not every generalized quasimetric on a set $X$ is a generalized metric on $X$.

Example 5. Let $X=\{t, 2 t, 3 t, 4 t, 5 t\}$ with $t>0$ as a constant, and we define $d: X \times X \rightarrow[0, \infty)$ by

(1) $d(x, x)=0$, for all $x \in X$;

(2) $d(t, 2 t)=d(2 t, t)=3 \gamma$;

(3) $d(t, 3 t)=d(2 t, 3 t)=d(3 t, t)=d(3 t, 2 t)=\gamma$;

(4) $d(t, 4 t)=d(2 t, 4 t)=d(3 t, 4 t)=d(4 t, t)=d(4 t, 2 t)=$ $d(4 t, 3 t)=2 \gamma$

(5) $d(t, 5 t)=d(2 t, 5 t)=d(3 t, 5 t)=d(4 t, 5 t)=(3 / 2) \gamma$;

(6) $d(5 t, t)=d(5 t, 2 t)=d(5 t, 3 t)=d(5 t, 4 t)=(5 / 4) \gamma$,

where $\gamma>0$ is a constant. Then, let $(X, d)$ be a generalized quasimetric space, but it is not a generalized metric space because

$$
d(t, 5 t)=\frac{3}{2} \gamma \neq d(5 t, t)=\frac{5}{4} \gamma
$$

We next give the definitions of convergence and completeness on generalized quasimetric spaces.
Definition 6. Let $(X, d)$ be a g.q.m.s, let $\left\{x_{n}\right\}$ be a sequence in $X$, and let $x \in X$. We say that $\left\{x_{n}\right\}$ is g.q.m.s convergent to $x$ if and only if

$$
\lim _{n \rightarrow \infty} d\left(x_{n}, x\right)=\lim _{n \rightarrow \infty} d\left(x, x_{n}\right)=0 .
$$

Definition 7. Let $(X, d)$ be a g.q.m.s and let $\left\{x_{n}\right\}$ be a sequence in $X$. We say that $\left\{x_{n}\right\}$ is left-Cauchy if and only if, for every $\varepsilon>0$, there exits $k \in \mathbb{N}$ such that $d\left(x_{n}, x_{m}\right)<\varepsilon$ for all $n \geq$ $m>k$.

Definition 8. Let $(X, d)$ be a g.q.m.s and let $\left\{x_{n}\right\}$ be a sequence in $X$. We say that $\left\{x_{n}\right\}$ is right-Cauchy if and only if, for every $\varepsilon>0$, there exits $k \in \mathbb{N}$ such that $d\left(x_{n}, x_{m}\right)<\varepsilon$ for all $m \geq$ $n>k$.

Definition 9. Let $(X, d)$ be a g.q.m.s and let $\left\{x_{n}\right\}$ be a sequence in $X$. We say that $\left\{x_{n}\right\}$ is Cauchy if and only if, for every $\varepsilon>0$, there exits $k \in \mathbb{N}$ such that $d\left(x_{n}, x_{m}\right)<\varepsilon$ for all $m, n>k$.

Remark 10. A sequence $\left\{x_{n}\right\}$ in a g.q.m.s is Cauchy if and only if it is left-Cauchy and right-Cauchy.

Definition 11. Let $(X, d)$ be a g.q.m.s. We say that

(1) $(X, d)$ is left-complete if and only if each left-Cauchy sequence in $X$ is convergent;

(2) $(X, d)$ is right-complete if and only if each rightCauchy sequence in $X$ is convergent;

(3) $(X, d)$ is complete if and only if each Cauchy sequence in $X$ is convergent.

In the sequel, we let the function $\phi:[0, \infty) \rightarrow[0, \infty)$ satisfy the following conditions:

$\left(\phi_{1}\right) \phi:[0, \infty) \rightarrow[0, \infty)$ is a nondecreasing weaker Meir-Keeler function;

$\left(\phi_{2}\right) \phi(t)>0$ for $t>0$ and $\phi(0)=0$;

$\left(\phi_{3}\right)$ for all $t \in(0, \infty),\left\{\phi^{n}(t)\right\}_{n \in \mathbb{N}}$ is decreasing;

$\left(\phi_{4}\right)$ for $t>0$, if $\lim _{n \rightarrow \infty} \phi^{n}(t)=0$, then $\lim _{n \rightarrow \infty} \sum_{i=n}^{m} \phi^{i}(t)=0$, where $m>n$.

Now, we recall the notion of $\alpha$-admissible mappings. The following definition was introduced in [3].

Definition 12. Let $f: X \rightarrow X$ be a self-mapping of a set $X$ and $\alpha: X \times X \rightarrow \mathbb{R}^{+}$. Then $f$ is called a $\alpha$-admissible if

$$
x, y \in X, \quad \alpha(x, y) \geq 1 \Longrightarrow \alpha(f x, f y) \geq 1 .
$$

In the sequel, we use the notion of triangular $\alpha$-admissible which was defined in [4] as follows.

Definition 13. Let $f: X \rightarrow X$ and $\alpha: X \times X \rightarrow[0, \infty)$. The mapping $f$ is said to be a triangular $\alpha$-admissible if, for all $x, y, z \in X$, we have

(1) for all $x, y \in X, \alpha(x, y) \geq 1$ implies $\alpha(f x, f y) \geq 1$;

(2) for all $x, y, z \in X, \alpha(x, y) \geq 1$ and $\alpha(y, z) \geq 1$ imply $\alpha(x, z) \geq 1$. 


\section{Main Results}

In this section we state our main result. First we introduce the notion of $(\alpha-\phi)$-weaker Meir-Keeler contractive mappings via the weaker Meir-Keeler function $\phi$ and the triangular $\alpha$ admissible mapping $\alpha$.

Definition 14. Let $(X, d)$ be a g.q.m.s, let $\alpha: X \times X \rightarrow \mathbb{R}^{+}$, and let $f: X \rightarrow X$ be a function satisfying

$$
\alpha(x, y) d(f x, f y) \leq \phi(d(x, y))
$$

for all $x, y \in X$. Then $f$ is said to be a $(\alpha-\phi)$-weaker MeirKeeler contractive mapping. lows.

Now, we state our main periodic point theorems as fol-

Theorem 15. Let $(X, d)$ be a Hausdorff and complete g.q.m.s, and let $f: X \rightarrow X$ be $a(\alpha-\phi)$-weaker Meir-Keeler contractive mapping. Suppose that

(i) $f$ is triangular $\alpha$-admissible;

(ii) there exists $x_{0} \in X$ such that $\alpha\left(x_{0}, f x_{0}\right) \geq 1$ and $\alpha\left(f x_{0}, x_{0}\right) \geq 1$

(iii) $f$ is continuous.

Then $f$ has a periodic point in $X$; that is, there exists a $u \in X$ such that $u=f^{p}(u)$ for some $p \in \mathbb{N}$.

Proof. Regarding the assumption (ii) of the theorem, we let $x_{0} \in X$ be an arbitrary point such that $\alpha\left(x_{0}, f x_{0}\right) \geq 1$ and $\alpha\left(x_{0}, f x_{0}\right) \geq 1$. We will construct a sequence $\left\{x_{n}\right\}$ in $X$ by $x_{n+1}=f x_{n}=f^{n+1} x_{0}$ for all $n \geq 0$. If we have $x_{n_{0}}=x_{n_{0}+1}$, for some $n_{0}$, then $u=x_{n_{0}}$ is a fixed point of $f$; that is, $u=x_{n_{0}}$ is a periodic point in $X$. Hence, for the rest of the proof, we presume that

$$
x_{n} \neq x_{n+1} \quad \forall n \text {. }
$$

Since $f$ is triangular $\alpha$-admissible, we also have

$$
\begin{aligned}
\alpha\left(x_{0}, x_{1}\right) & =\alpha\left(x_{0}, f x_{0}\right) \geq 1 \\
& \Longrightarrow \alpha\left(f x_{0}, f x_{1}\right)=\alpha\left(x_{1}, x_{2}\right) \geq 1 .
\end{aligned}
$$

Utilizing the expression above, we obtain that

$$
\alpha\left(x_{n}, x_{n+1}\right) \geq 1, \quad \forall n=0,1, \ldots
$$

By repeating the same steps with starting with the assumption $\alpha\left(x_{1}, x_{0}\right)=\alpha\left(f x_{0}, x_{0}\right) \geq 1$, we conclude that

$$
\alpha\left(x_{n+1}, x_{n}\right) \geq 1, \quad \forall n=0,1, \ldots
$$

Since, $f$ is triangular $\alpha$-admissible, we derive that

$$
\alpha\left(x_{0}, x_{1}\right) \geq 1, \quad \alpha\left(x_{1}, x_{2}\right) \geq 1 \Longrightarrow \alpha\left(x_{0}, x_{2}\right) \geq 1 .
$$

Recursively, we get that

$$
\alpha\left(x_{n}, x_{n+k}\right) \geq 1, \quad \forall n=0,1, \ldots, k=1,2, \ldots
$$

Analogously, we can easily derive that

$$
\alpha\left(x_{n+k}, x_{n}\right) \geq 1, \quad \forall n=0,1, \ldots, k=1,2, \ldots
$$

In the sequel, we prove that the sequence $\left\{x_{n}\right\}$ is Cauchy; that is, $\left\{x_{n}\right\}$ is both right-Cauchy and left-Cauchy.

Step 1. We first assert that

$$
\lim _{n \rightarrow \infty} d\left(x_{n}, x_{n+1}\right)=0 .
$$

Regarding (5) and (8), we deduce that

$$
\begin{aligned}
d\left(x_{n}, x_{n+1}\right) & =d\left(f x_{n-1}, f x_{n}\right) \\
& \leq \alpha\left(x_{n-1}, x_{n}\right) d\left(f x_{n-1}, f x_{n}\right) \\
& \leq \phi\left(d\left(x_{n-1}, x_{n}\right)\right),
\end{aligned}
$$

for all $n \geq 1$. Since $\phi$ is nondecreasing, by iteration, we derive the following inequality:

$$
\begin{aligned}
d\left(x_{n}, x_{n+1}\right) & \leq \phi\left(d\left(x_{n-1}, x_{n}\right)\right) \\
& \leq \phi\left(\phi\left(d\left(x_{n-2}, x_{n-1}\right)\right)\right) \\
& =\phi^{2}\left(d\left(x_{n-3}, x_{n-2}\right)\right) \leq \cdots \\
& \leq \phi^{n}\left(d\left(x_{0}, x_{1}\right)\right) .
\end{aligned}
$$

Since $\left\{\phi^{n}\left(d\left(x_{0}, x_{1}\right)\right)\right\}_{n \in \mathbb{N}}$ is decreasing, it must converge to some $\eta \geq 0$. We claim that $\eta=0$. Suppose that, on the contrary, $\eta>0$. Then by the definition of weaker Meir-Keeler function $\phi$, corresponding to the given $\eta$, there exists $\delta>0$ such that, for $x_{0}, x_{1} \in X$ with $\eta \leq d\left(x_{0}, x_{1}\right)<\delta+\eta$, and $n_{0} \in \mathbb{N}$ such that $\phi^{n_{0}}\left(d\left(x_{0}, x_{1}\right)\right)<\eta$. Since $\lim _{n \rightarrow \infty} \phi^{n}\left(d\left(x_{0}, x_{1}\right)\right)=\eta$, there exists $p_{0} \in \mathbb{N}$ such that $\eta \leq \phi^{p}\left(d\left(x_{0}, x_{1}\right)\right)<\delta+\eta$, for all $p \geq p_{0}$. Thus, we conclude that $\phi^{p_{0}+n_{0}}\left(d\left(x_{0}, x_{1}\right)\right)<\eta$, which is a contradiction. Therefore $\lim _{n \rightarrow \infty} \phi^{n}\left(d\left(x_{0}, x_{1}\right)\right)=0$; that is,

$$
\lim _{n \rightarrow \infty} d\left(x_{n}, x_{n+1}\right)=0
$$

Step 2. We will show that

$$
\lim _{n \rightarrow \infty} d\left(x_{n}, x_{n+2}\right)=0 \text {. }
$$

We repeat the same argument that was used in Step 1. On account of (5) and (11), we observe that

$$
\begin{aligned}
& d\left(x_{n}, x_{n+2}\right) \\
& \quad=d\left(f x_{n-1}, f x_{n+1}\right) \\
& \quad \leq \alpha\left(x_{n+1}, x_{n-1}\right) d\left(f x_{n-1}, f x_{n+1}\right) \\
& \quad \leq \phi\left(d\left(x_{n-1}, x_{n+1}\right)\right),
\end{aligned}
$$

for all $n \geq 1$. Since $\phi$ is nondecreasing, by iteration, we derive the following inequality:

$$
\begin{aligned}
d\left(x_{n}, x_{n+2}\right) & \leq \phi\left(d\left(x_{n-1}, x_{n+1}\right)\right) \\
& \leq \phi\left(\phi\left(d\left(x_{n-2}, x_{n}\right)\right)\right) \\
& =\phi^{2}\left(d\left(x_{n-3}, x_{n-1}\right)\right) \leq \cdots \\
& \leq \phi^{n}\left(d\left(x_{0}, x_{2}\right)\right) .
\end{aligned}
$$


Since $\left\{\phi^{n}\left(d\left(x_{0}, x_{2}\right)\right)\right\}_{n \in \mathbb{N}}$ is decreasing, it must converge to some $\eta \geq 0$. We claim that $\eta=0$. Suppose that, on the contrary, $\eta>0$. Then by the definition of weaker MeirKeeler function $\phi$, corresponding to the given $\eta$, there exists $\delta>0$ such that, for $x_{0}, x_{2} \in X$ with $\eta \leq d\left(x_{0}, x_{2}\right)<$ $\delta+\eta$, and $n_{0} \in \mathbb{N}$ such that $\phi^{n_{0}}\left(d\left(x_{0}, x_{2}\right)\right)<\eta$. Since $\lim _{n \rightarrow \infty} \phi^{n}\left(\varphi\left(d\left(x_{0}, x_{2}\right)\right)\right)=\eta$, there exists $p_{0} \in \mathbb{N}$ such that $\eta \leq \phi^{p}\left(d\left(x_{0}, x_{2}\right)\right)<\delta+\eta$, for all $p \geq p_{0}$. Thus, we conclude that $\phi^{p_{0}+n_{0}}\left(d\left(x_{0}, x_{2}\right)\right)<\eta$, which is a contradiction. Therefore $\lim _{n \rightarrow \infty} \phi^{n}\left(d\left(x_{0}, x_{2}\right)\right)=0$; that is,

$$
\lim _{n \rightarrow \infty} d\left(x_{n}, x_{n+2}\right)=0
$$

Step 3. We next will prove that the sequence $\left\{x_{n}\right\}$ is rightCauchy by standard technique. For this purpose, it is sufficient to examine two cases.

Case (I). Suppose that $k>2$ and $k$ is odd. Let $k=2 m+1$, $k \geq 1$. Then, by using the quadrilateral inequality, we have

$$
\begin{aligned}
d\left(x_{n}, x_{n+k}\right)= & d\left(x_{n}, x_{n+2 m+1}\right) \\
\leq & d\left(x_{n}, x_{n+1}\right)+d\left(x_{n+1}, x_{n+2}\right) \\
& +d\left(x_{n+2}, x_{n+2 m+1}\right) \\
\leq & d\left(x_{n}, x_{n+1}\right)+d\left(x_{n+1}, x_{n+2}\right) \\
& +d\left(x_{n+2}, x_{n+3}\right)+\cdots \\
& +d\left(x_{n+2 m}, x_{n+2 m+1}\right) \\
= & d\left(f x_{n-1}, f x_{n}\right)+d\left(f x_{n}, f x_{n+1}\right) \\
& +d\left(f x_{n+1}, f x_{n+2}\right)+\cdots \\
& +d\left(f x_{n+2 m-1}, x_{n+2 m}\right) \\
\leq & \alpha\left(x_{n-1}, x_{n}\right) d\left(f x_{n-1}, f x_{n}\right) \\
& +\alpha\left(x_{n}, x_{n+1}\right) d\left(f x_{n}, f x_{n+1}\right) \\
& +\alpha\left(x_{n+1}, x_{n+2}\right) d\left(f x_{n+1}, f x_{n+2}\right)+\cdots \\
& +\alpha\left(x_{n+2 m-1}, x_{n+2 m}\right) d\left(f x_{n+2 m-1}, x_{n+2 m}\right) \\
\leq & \cdots \leq \phi^{n}\left(d\left(x_{0}, x_{1}\right)\right) \\
& +\phi^{n+1}\left(d\left(x_{0}, x_{1}\right)\right) \\
& \left.+0\left(x_{0}, x_{1}\right)\right)+\cdots+\phi^{n+2 m}\left(d\left(x_{0}, x_{1}\right)\right) \\
& \left.\left.+x_{1}\right)\right) \\
& +\cdots \\
&
\end{aligned}
$$

Let $n \rightarrow \infty$. Then, by using condition $\phi_{4}$, we have

$$
\lim _{n \rightarrow \infty} d\left(x_{n}, x_{n+k}\right)=0 .
$$

Case (II). Suppose that $k>2$ and $k$ is even. Let $k=2 m, k \geq 1$. Then, by using the quadrilateral inequality, we also have

$$
\begin{aligned}
d\left(x_{n}, x_{n+k}\right)= & d\left(x_{n}, x_{n+2 m}\right) \\
\leq & d\left(x_{n}, x_{n+2}\right)+d\left(x_{n+2}, x_{n+4}\right) \\
& +d\left(x_{n+4}, x_{n+2 m}\right) \\
\leq & d\left(x_{n}, x_{n+2}\right)+d\left(x_{n+2}, x_{n+4}\right) \\
& +d\left(x_{n+4}, x_{n+6}\right)+\cdots+d\left(x_{n+2 m-2}, x_{n+2 m}\right) \\
= & d\left(f x_{n-1}, f x_{n+1}\right)+d\left(f x_{n+1}, f x_{n+3}\right) \\
& +d\left(f x_{n+3}, f x_{n+5}\right)+\cdots \\
& +d\left(f x_{n+2 m-3}, f x_{n+2 m-1}\right) \\
\leq & \alpha\left(x_{n-1}, x_{n+1}\right) d\left(f x_{n-1}, f x_{n+1}\right) \\
& +\alpha\left(x_{n+1}, x_{n+3}\right) d\left(f x_{n+1}, f x_{n+3}\right) \\
& +\alpha\left(x_{n+3}, x_{n+5}\right) d\left(f x_{n+3}, f x_{n+5}\right)+\cdots \\
& +\alpha\left(x_{n+2 m-3}, x_{n+2 m-1}\right) \\
& \times d\left(f x_{n+2 m-3}, f x_{n+2 m-1}\right) \leq \cdots \\
\leq & \phi^{n}\left(d\left(x_{0}, x_{2}\right)\right) \\
& +\phi^{n+2}\left(d\left(x_{0}, x_{2}\right)\right) \\
& +\phi^{n+4}\left(d\left(x_{0}, x_{2}\right)\right)+\cdots+\phi^{n+2 m}\left(d\left(x_{0}, x_{2}\right)\right) \\
& \left.+d\left(x_{0}, x_{2}\right)\right) . \\
& +\cdots
\end{aligned}
$$

Let $n \rightarrow \infty$. Then, by using condition $\phi_{4}$, we have

$$
\lim _{n \rightarrow \infty} d\left(x_{n}, x_{n+k}\right)=0 \text {. }
$$

By above argument, we get that $\left\{x_{n}\right\}$ is a right-Cauchy sequence.

Analogously, we derive that the sequence $\left\{x_{n}\right\}$ is leftCauchy. Consequently, the sequence $\left\{x_{n}\right\}$ is Cauchy. Since $X$ is a complete g.q.m.s, there exists $u \in X$ such that

$$
\lim _{n \rightarrow \infty} d\left(x_{n}, u\right)=\lim _{n \rightarrow \infty} d\left(u, x_{n}\right)=0 .
$$

Step 4. We claim that $f$ has a periodic point in $X$. Suppose that, on the contrary, $f$ has no periodic point. Since $f$ is continuous, we obtain from (25) that

$$
\begin{aligned}
& \lim _{n \rightarrow \infty} d\left(x_{n+1}, f u\right)=\lim _{n \rightarrow \infty} d\left(f x_{n}, f u\right)=0, \\
& \lim _{n \rightarrow \infty} d\left(f u, x_{n+1}\right)=\lim _{n \rightarrow \infty} d\left(f u, f x_{n}\right)=0 .
\end{aligned}
$$

From (25) and (26), we get immediately that $\lim _{n \rightarrow \infty} f^{n} x_{0}=$ $\lim _{n \rightarrow \infty} f x_{n}=f u$. As $(X, d)$ is Hausdorff, we conclude that 
$u=f u$ which contradicts the assumption that $f$ has no periodic point. Therefore, there exists $u \in X$ such that $u=f^{p}(u)$ for some $p \in \mathbb{N}$. So $f$ has a periodic point in $X$.

Following the proof of Theorem 15, we can easily get the following periodic point theorem.

Theorem 16. Let $(X, d)$ be a Hausdorff and complete g.q.m.s, and let $f: X \rightarrow X$ be a $(\alpha-\phi-\varphi)$-weaker Meir-Keeler contractive mapping. Suppose that

(i) $f$ is triangular $\alpha$-admissible;

(ii) there exists $x_{0} \in X$ such that $\alpha\left(x_{0}, f x_{0}\right) \geq 1$ and $\alpha\left(f x_{0}, x_{0}\right) \geq 1$;

(iii) if $\left\{x_{n}\right\}$ is a sequence in $X$ such that $\alpha\left(x_{n}, x_{n+1}\right) \geq 1$ and $\alpha\left(x_{n+1}, x_{n}\right) \geq 1$ for all $n$ and $x_{n} \rightarrow x \in X$ as $n \rightarrow \infty$, then $\alpha\left(x_{n}, x\right) \geq 1$ and $\alpha\left(x, x_{n}\right) \geq 1$ for all $n$.

Then $f$ has a periodic point in $X$.

Proof. Following the proof of Theorem 15, we know that the sequence $\left\{x_{n}\right\}$ defined by $x_{n+1}=f x_{n}$, for all $n \geq 0$, converges for some $u \in X$. From (25) and condition (iii), there exists a subsequence $\left\{x_{n(k)}\right\}$ of $\left\{x_{n}\right\}$ such that $\alpha\left(x_{n(k)}, u\right) \geq 1$ for all $k$. Applying (5), for all $k$, we get that

$$
\begin{aligned}
d\left(x_{n(k)+1}, f u\right) & =d\left(f x_{n(k)}, f u\right) \\
& \leq \alpha\left(x_{n(k)}, u\right) d\left(f x_{n(k)}, f u\right) \\
& \leq \phi\left(d\left(x_{n(k)}, u\right)\right), \\
d\left(f u, x_{n(k)+1}\right) & =d\left(f u, f x_{n(k)}\right) \\
& \leq \alpha\left(u, x_{n(k)}\right) d\left(f u, f x_{n(k)}\right) \\
& \leq \phi\left(u, d\left(x_{n(k)}\right)\right) .
\end{aligned}
$$

Letting $k \rightarrow \infty$ in the above equality, we find that

$$
\begin{aligned}
& d\left(x_{n(k)+1}, f u\right)=\lim _{k \rightarrow \infty} d\left(f x_{n(k)}, f u\right)=0, \\
& d\left(f u, x_{n(k)+1}\right)=\lim _{k \rightarrow \infty} d\left(f u, f x_{n(k)}\right)=0 .
\end{aligned}
$$

Therefore, we have $\lim _{k \rightarrow \infty} f^{n(k)} x_{0}=\lim _{k \rightarrow \infty} f x_{n(k)}=f u$. As $(X, d)$ is Hausdorff, we conclude that $u=f u$ which contradicts the assumption that $f$ has no periodic point. Therefore, there exists $u \in X$ such that $u=f^{p}(u)$ for some $p \in \mathbb{N}$. So $f$ has a periodic point in $X$.

\section{Consequences}

Using the weaker Meir-Keeler function $\phi$, we introduce the notion of $\phi$-weaker Meir-Keeler contractive mappings and prove a theorem which assures the existence of a periodic point for these mappings on generalized quasimetric spaces.

Definition 17. Let $(X, d)$ be a g.q.m.s, and let $f: X \rightarrow X$ be a function satisfying

$$
d(f x, f y) \leq \phi(d(x, y))
$$

for all $x, y \in X$. Then $f$ is said to be a $\phi$-weaker Meir-Keeler contractive mapping.

Theorem 18. Let $(X, d)$ be a Hausdorff and complete g.q.m.s, and let $f$ be a $\phi$-weaker Meir-Keeler contractive mapping. Suppose that $f$ is continuous. Then $f$ has a periodic point $u$ in $X$; that is, there exists $u \in X$ such that $u=f^{p} u$ for some $p \in \mathbb{N}$.

Proof. It is sufficient to take $\alpha(x, y)=1$, for all $x, y \in X$, in Theorem 15.

Theorem 19. Let $(X, d)$ be a Hausdorff and complete g.q.m.s. Suppose that $f$ is continuous and there exists $k \in[0,1)$ such that

$$
d(f x, f y) \leq k d(x, y)
$$

for all $x, y \in X$. Then $f$ has a periodic point $u$ in $X$; that is, there exists $u \in X$ such that $u=f^{p} u$ for some $p \in \mathbb{N}$.

Proof. It is sufficient to take $\phi(t)=k t$, for all $x, y \in X$, in Theorem 18 , where $k \in[0,1)$.

Definition 20 . Let $(X, \preceq)$ be a partially ordered set and let $T$ : $X \rightarrow X$ be a given mapping. We say that $T$ is nondecreasing with respect to $\preceq$ if

$$
x, y \in X, \quad x \preceq y \Longrightarrow T x \preceq T y .
$$

Definition 21 . Let $(X, \preceq)$ be a partially ordered set. A sequence $\left\{x_{n}\right\} \subset X$ is said to be nondecreasing with respect to $\preceq$ if $x_{n} \preceq$ $x_{n+1}$ for all $n$.

Definition 22 . Let $(X, \preceq)$ be a partially ordered set and let $d$ be a metric on $X$. We say that $(X, \preceq, d)$ is regular if, for every nondecreasing sequence $\left\{x_{n}\right\} \subset X$ such that $x_{n} \rightarrow x \in X$ as $n \rightarrow \infty$, we have $x_{n} \preceq x$ for all $n$.

We have the following result.

Corollary 23. Let $(X, \preceq)$ be a partially ordered set and let $d$ be a metric on $X$ such that $(X, d)$ is complete. Let $f: X \rightarrow X$ be a nondecreasing mapping with respect to $\preceq$. Suppose that there exists a function $\phi$ such that

$$
d(f x, f y) \leq \phi(d(x, y))
$$

for all $x, y \in X$ with $x \geq y$. Suppose also that the following conditions hold:

(i) there exists $x_{0} \in X$ such that $x_{0} \preceq f x_{0}$;

(ii) $f$ is continuous or $(X, \preceq, d)$ is regular.

Then $f$ has a periodic point.

Proof. Define the mapping $\alpha: X \times X \rightarrow[0, \infty)$ by

$$
\alpha(x, y)= \begin{cases}1 & \text { if } x \preceq y \text { or } x \geq y \\ 0 & \text { otherwise }\end{cases}
$$


It is evident that $f$ is a $(\alpha-\phi)$ contractive mapping; that is,

$$
\alpha(x, y) d(f x, f y) \leq \psi(d(x, y))
$$

for all $x, y \in X$. From condition (i), we have that $\alpha\left(x_{0}, f x_{0}\right) \geq$ 1 and $\alpha\left(f x_{0}, x_{0}\right) \geq 1$. Moreover, for all $x, y \in X$, from the monotone property of $f$, we have

$$
\begin{aligned}
\alpha(x, y) \geq 1 & \Longrightarrow x \geq y \text { or } x \preceq y \\
& \Longrightarrow f x \geq f y \text { or } f x \preceq f y \\
& \Longrightarrow \alpha(f x, f y) \geq 1 .
\end{aligned}
$$

Thus $f$ is $\alpha$-admissible. Now, if $f$ is continuous, the existence of a fixed point follows from Theorem 15. Suppose now that $(X, \preceq, d)$ is regular. Let $\left\{x_{n}\right\}$ be a sequence in $X$ such that $\alpha\left(x_{n}, x_{n+1}\right) \geq 1$ for all $n$ and $x_{n} \rightarrow x \in X$ as $n \rightarrow \infty$. From the regularity hypothesis, we have $x_{n} \preceq x$ for all $n$. This implies from the definition of $\alpha$ that $\alpha\left(x_{n}, x\right) \geq 1$ for all $n$. In this case, the existence of a fixed point follows from Theorem 16.

Corollary 24. Let $(X, \preceq)$ be a partially ordered set and let d be a metric on $X$ such that $(X, d)$ is complete. Let $f: X \rightarrow X$ be a nondecreasing mapping with respect to $\preceq$. Suppose that there exists a function $k \in(0,1)$ such that

$$
d(f x, f y) \leq k d(x, y)
$$

for all $x, y \in X$ with $x \geq y$. Suppose also that the following conditions hold:

(i) there exists $x_{0} \in X$ such that $x_{0} \preceq f x_{0}$;

(ii) $f$ is continuous or $(X, \preceq, d)$ is regular.

Then $f$ has a periodic point.

Proof. It is sufficient to take $\phi(t)=k t$, for all $x, y \in X$, in the corollary above, where $k \in[0,1)$.

\section{Conflict of Interests}

The authors declare that there is no conflict of interests regarding the publication of this paper.

\section{References}

[1] A. Branciari, "A fixed point theorem of Banach-Caccioppoli type on a class of generalized metric spaces," Publicationes Mathematicae Debrecen, vol. 57, no. 1-2, pp. 31-37, 2000.

[2] E. Karapınar, "Discussion on $\alpha-\psi$ contractions on generalized metric spaces," Abstract and Applied Analysis, vol. 2014, Article ID 962784, 7 pages, 2014.

[3] B. Samet, C. Vetro, and P. Vetro, "Fixed point theorems for $\alpha-\psi$-contractive type mappings," Nonlinear Analysis: Theory, Methods \& Applications, vol. 75, no. 4, pp. 2154-2165, 2012.

[4] E. Karapinar, P. Kumam, and P. Salimi, "On $\alpha-\psi$-Meir-Keeler contractive mappings," Fixed Point Theory and Applications, vol. 2013, article 94, 2013.
[5] A. Azam and M. Arshad, "Kannan fixed point theorem on generalized metric spaces," Journal of Nonlinear Sciences and Its Applications, vol. 1, no. 1, pp. 45-48, 2008.

[6] M. A. Alghamdi, C.-M. Chen, and E. Karapınar, "The generalized weaker $(\alpha-\phi-\varphi)$-contractive mappings and related fixed point results in complete generalized metric spaces," Abstract and Applied Analysis, vol. 2014, Article ID 985080, 10 pages, 2014.

[7] P. Das, "A fixed point theorem on a class of generalized metric spaces," Korean Journal of Mathematical Sciences, vol. 9, pp. 2933, 2002.

[8] I. M. Erhan, E. Karapınar, and T. Sekulic, "Fixed points of $(\psi, \phi)$ contractions on rectangular metric spaces," Fixed Point Theory and Applications, vol. 2012, article 138, 2012.

[9] D. Miheţ, "On Kannan fixed point principle in generalized metric spaces," Journal of Nonlinear Science and Its Applications, vol. 2, no. 2, pp. 92-96, 2009.

[10] B. Samet, "A fixed point theorem in a generalized metric space for mappings satisfying a contractive condition of integral type," International Journal of Mathematical Analysis, vol. 3, no. 25-28, pp. 1265-1271, 2009.

[11] B. Samet, "Discussion on 'a fixed point theorem of BanachCaccioppoli type on a class of generalized metric spaces," Publicationes Mathematicae Debrecen, vol. 76, no. 3-4, pp. 493494, 2010.

[12] H. Lakzian and B. Samet, "Fixed points for $(\psi, \varphi)$-weakly contractive mappings in generalized metric spaces," Applied Mathematics Letters, vol. 25, no. 5, pp. 902-906, 2012.

[13] M. S. Khan, M. Swaleh, and S. Sessa, "Fixed point theorems by altering distances between the points," Bulletin of the Australian Mathematical Society, vol. 30, no. 1, pp. 1-9, 1984.

[14] A. Meir and E. Keeler, "A theorem on contraction mappings," Journal of Mathematical Analysis and Applications, vol. 28, pp. 326-329, 1969.

[15] A. A. Eldred and P. Veeramani, "Existence and convergence of best proximity points," Journal of Mathematical Analysis and Applications, vol. 323, no. 2, pp. 1001-1006, 2006.

[16] M. de la Sen, "Linking contractive self-mappings and cyclic Meir-Keeler contractions with Kannan self-mappings," Fixed Point Theory and Applications, vol. 2010, Article ID 572057, 23 pages, 2010.

[17] M. Jleli and B. Samet, "The Kannan's fixed point theorem in a cone rectangular metric space," Journal of Nonlinear Science and Its Applications, vol. 2, no. 3, pp. 161-167, 2009.

[18] W. A. Kirk and N. Shahzad, "Generalized metrics and Caristis theorem," Fixed Point Theory and Applications, vol. 2013, article 129,2013 


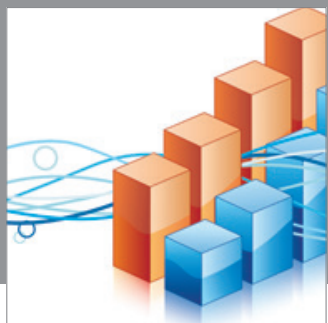

Advances in

Operations Research

mansans

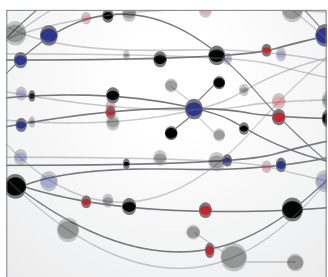

The Scientific World Journal
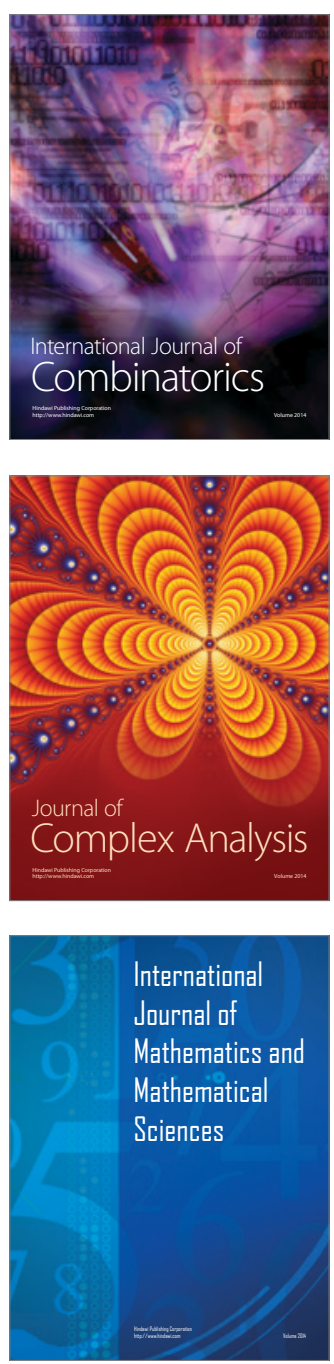
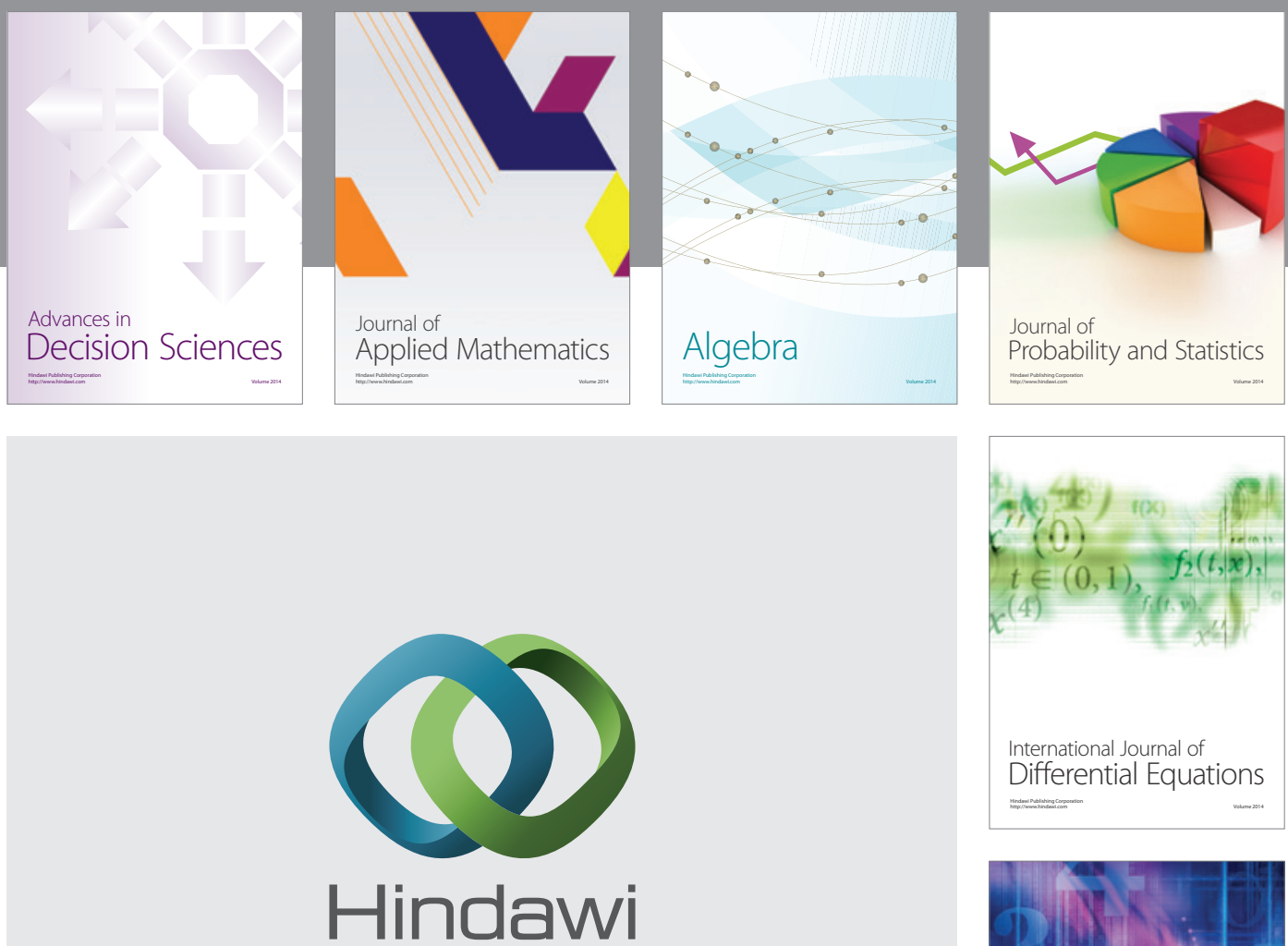

Submit your manuscripts at http://www.hindawi.com
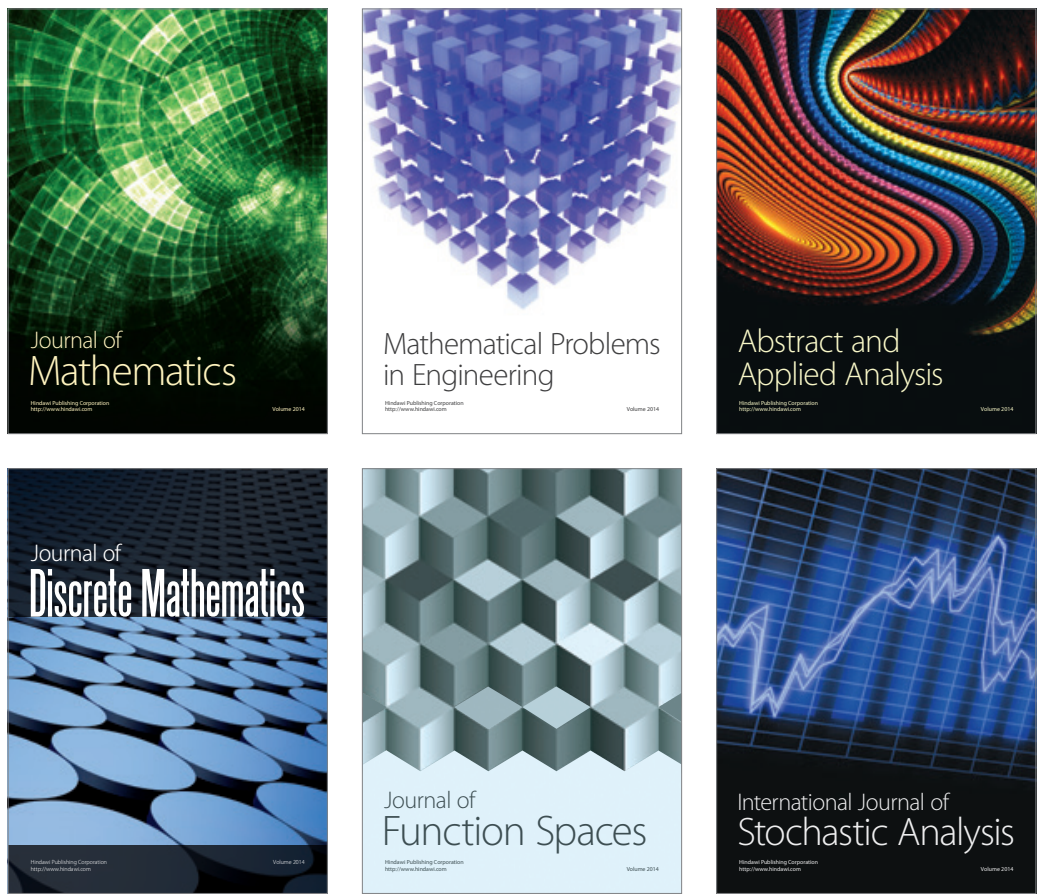

Journal of

Function Spaces

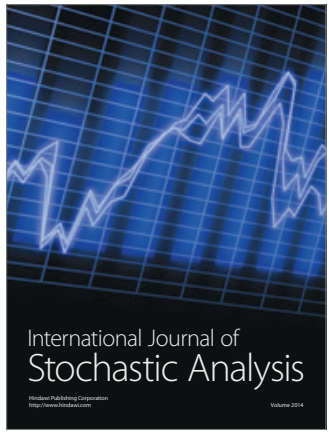

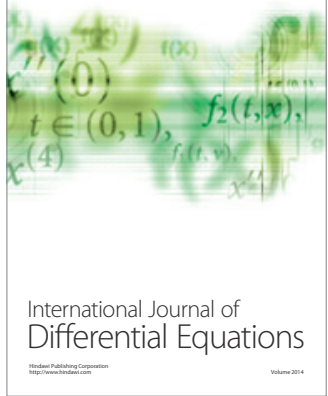
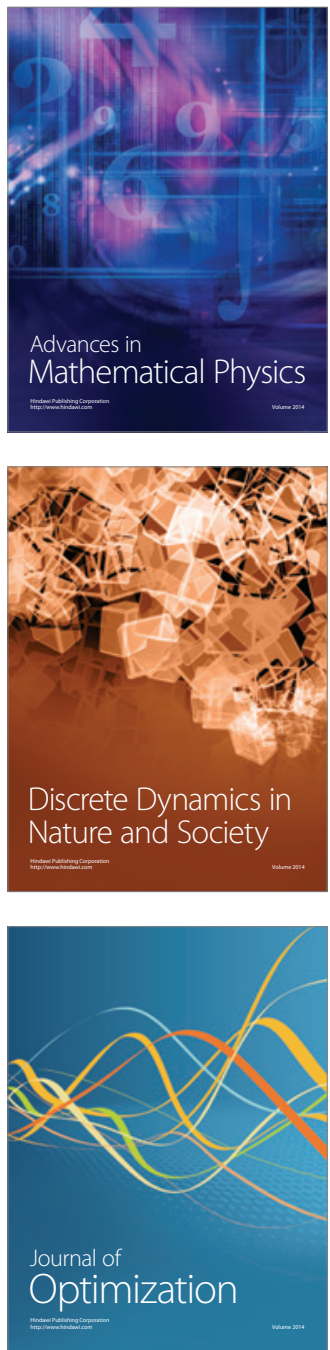